\title{
Using Mountain Lion Habitat Selection in Management
}

\author{
JUSTIN A. DELLINGER (D), ${ }^{1}$ California Department of Fish and Wildlife, 1701 Nimbus Rd., Suite D, Rancho Cordova, CA 95670, USA \\ BOGDAN CRISTESCU, Center for Integrated Spatial Research, Environmental Studies Department, University of California, 1156 High St., \\ Santa Cruz, CA 95064, USA \\ JONATHAN EWANYK, Institute for Wildife Studies, PO Box 1104, Arcata, CA 95518, USA \\ DANIEL J. GAMMONS, California Department of Fish and Wildlife, 787 N Main St., Suite 220, Bishop, CA 93514, USA \\ DAVID GARCELON, Institute for Wildlife Studies, PO Box 1104, Arcata, CA 95518, USA \\ PHILLIP JOHNSTON, Hoopa Tribal Forestry Program, 40 Orchard St., Hoopa, CA 95546, USA \\ QUINTON MARTINS, Audubon Canyon Ranch, PO Box 577, Stinson Beach, CA 94970, USA \\ CRAIG THOMPSON, United States Forest Service, Northern Region, 26 Fort Missoula Rd., Missoula, MT 59804, USA \\ T. WINSTON VICKERS, Wildlife Health Center, University of California, 1089 Veterinary Medicine Dr., Davis, CA 95616, USA \\ CHRISTOPHER C. WILMERS, Center for Integrated Spatial Research, Environmental Studies Department, University of California, 1156 High St., \\ Santa Cruz, CA 95064, USA \\ HEIKO U. WITTMER, School of Biological Sciences, Victoria University of Wellington, PO Box 600, Wellington 6140, NZ \\ STEVEN G. TORRES, ${ }^{2}$ California Department of Fish and Wildlife, 1701 Nimbus Rd., Suite D, Rancho Cordova, CA 95670, USA
}

\begin{abstract}
Wildlife agencies are generally tasked with managing and conserving species at state and local levels simultaneously. Thus, it is necessary for wildlife agencies to understand basic ecological processes of a given species at multiple scales to aid decision making at commensurately varied spatial and behavioral scales. Mountain lions (Puma concolor) occur throughout California, USA, and are at the center of a variety of management and conservation issues. For example, they are genetically and demographically at risk in 1 region yet apparently stable and negatively affecting endangered species in another. Currently, no formal plan exists for mountain lions in California to deal with these diverse scenarios involving issues of local mountain lion population viability and problems related to predation of endangered species. To facilitate development of a state-wide management and conservation plan, we quantified habitat selection by mountain lions at 2 spatial scales across the range of environmental conditions in which the species is found in California. Our analyses used location data from individuals $(n=263)$ collared across the state from 2001-2019. At the home range scale, mountain lions selected habitat to prioritize meeting energetic demands. At the within home range scale, mountain lions avoided areas of human activity. Further, our analyses revealed $165,350-170,085 \mathrm{~km}^{2}$, depending on season, of suitable mountain lion habitat in California. Fifty percent of the suitable habitat was on unprotected lands and thus vulnerable to development. These habitat selection models will help in the development of a state-wide conservation and management plan for mountain lions in California by guiding mountain lion population monitoring through time, prioritization of habitat to be conserved for maintaining demographic connectivity and gene flow, and efforts to mediate mountain lion-prey interactions. Our work and application area will help with wildlife policy and management decisions related to depredation problems at the local scale and issues of habitat connectivity at the statewide scale. (C) 2019 The Wildlife Society.
\end{abstract}

KEY WORDS habitat modeling, landscape planning, mountain lion, Puma concolor, resource selection.

Wildlife managers are mandated by laws and regulations to ensure species viability across large jurisdictions (e.g., states, provinces, countries; Robinson et al. 2016, Ryder 2018). Understanding factors associated with habitat selection is key in helping wildlife managers ensure species persistence across

Received: 1 March 2019; Accepted: 26 October 2019

${ }^{1}$ E-mail: Justin.dellinger@wildlife.ca.gov

${ }^{2}$ Retired. large areas and can also facilitate development of strategies to deal with localized issues (Morrison and Matthewson 2015). Thus, quantifying habitat selection patterns provides the primary explanatory variable for managing wildlife at multiple spatial scales (Zeller et al. 2017).

Mountain lions (Puma concolor) are the most widely distributed mammal species in the Western Hemisphere (Hornocker and Negri 2010). In the western United States, where mountain lions are continuously distributed (Pierce and Bleich 2003), most states classify them as game animals 
and manage populations to provide hunting and other recreational opportunities and mitigate perceived or actual negative effects on other game species (i.e., ungulates) and livestock (Mattson 2014). In contrast, mountain lions in California, USA, are classified as a specially protected mammal (California Fish and Game Commission 2018), in which take is permitted only if a depredation permit is issued from California Department of Fish and Wildlife (CDFW) to take a specific mountain lion that is killing livestock or pets, to preserve public safety, or to protect state and federally listed bighorn sheep (Ovis canadensis).

Although mountain lions are not threatened or endangered in California, some local populations are currently at risk of extirpation because of habitat loss (Benson et al. 2016) and continued land-use change will put additional populations at risk (Gustafson et al. 2019). In some areas of the state, mountain lions negatively affect large ungulates (Hudgens et al. 2016, Conner et al. 2018). Overall, there is a general lack of understanding about mountain lion abundance and population trends statewide and a need for detailed information on distribution and habitat selection. Although mountain lions are widespread in California (Pierce et al. 1999, Wilmers et al. 2013, Vickers et al. 2015, McClanahan et al. 2017, Dellinger et al. 2018) and lack one of the most common mortality sources that they experience elsewhere (i.e., regulated hunting), little is known about them outside of a few small isolated populations adjacent to major human population centers (Wilmers et al. 2013, Vickers et al. 2015, Benson et al. 2016). Thus, policy makers and wildlife biologists lack the basic information needed for science-based management and conservation of mountain lions across California.

Some management and conservation challenges occur throughout the state, such as livestock depredation, but given the size $\left(423,971 \mathrm{~km}^{2}\right)$, diversity of ecoregions (Fig. 1), and diversity of human development (i.e., 8 of the 50 most populous cities in the country but with $50 \%$ of its land in public ownership; U.S. Geological Survey 2017), a range of area-specific management and conservation challenges exist. For example, in southern California, mountain lions have become genetically isolated because of human development and persist in a highly fragmented landscape (Vickers et al. 2015, Benson et al. 2016). In contrast, mountain lions in the eastern Sierra Nevada mountains occur in a largely undeveloped landscape but are of management concern because of their predation upon federally listed Sierra Nevada bighorn sheep (Ovis canadensis sierrae; Johnson et al. 2013).

Recognizing the challenges facing policy makers and wildlife biologists, in 2014 CDFW began a project to estimate the abundance of mountain lions statewide and develop region-specific long-term monitoring approaches, with the goal of producing a state-wide management and conservation plan. Previous work by Torres et al. (1996) attempted to demonstrate distribution and quality of mountain lion habitat in California in a habitat suitability framework by ranking habitat characteristics based on expert opinion. Since this time, raw data have been accumulated to assess mountain lion habitat selection patterns directly and with more modern spatial and statistical techniques (Wilmers et al. 2013, Zeller et al. 2017). In support of this effort, our objectives were to use mountain lion location data obtained from 13 areas across California (Table 1) to develop multi-scale seasonal resource selection functions. We evaluated patterns of habitat selection across California and determine amount, distribution, and status (i.e., public vs. private land) of suitable mountain lion habitat across California to assist in prioritizing habitat
A

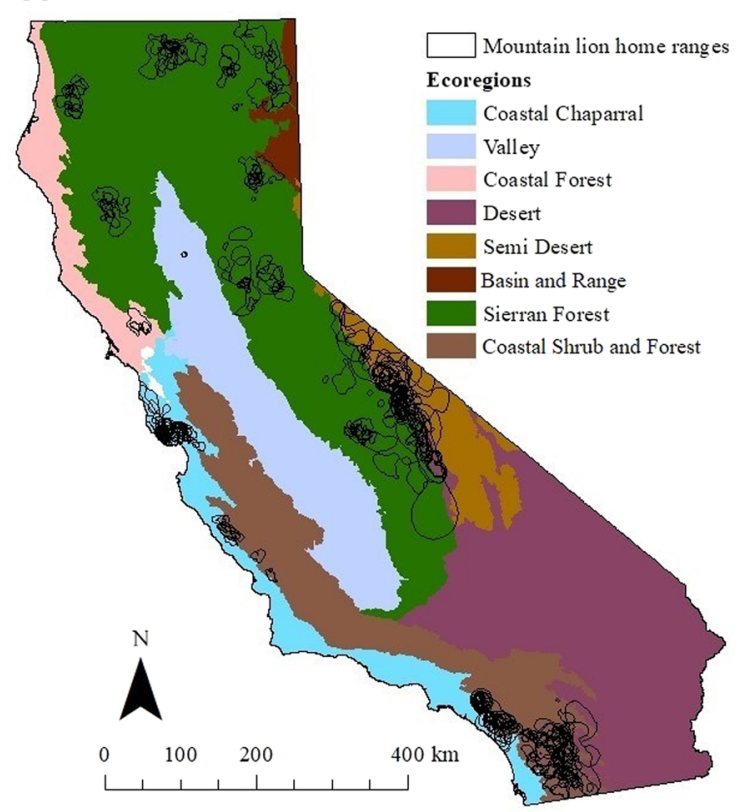

B

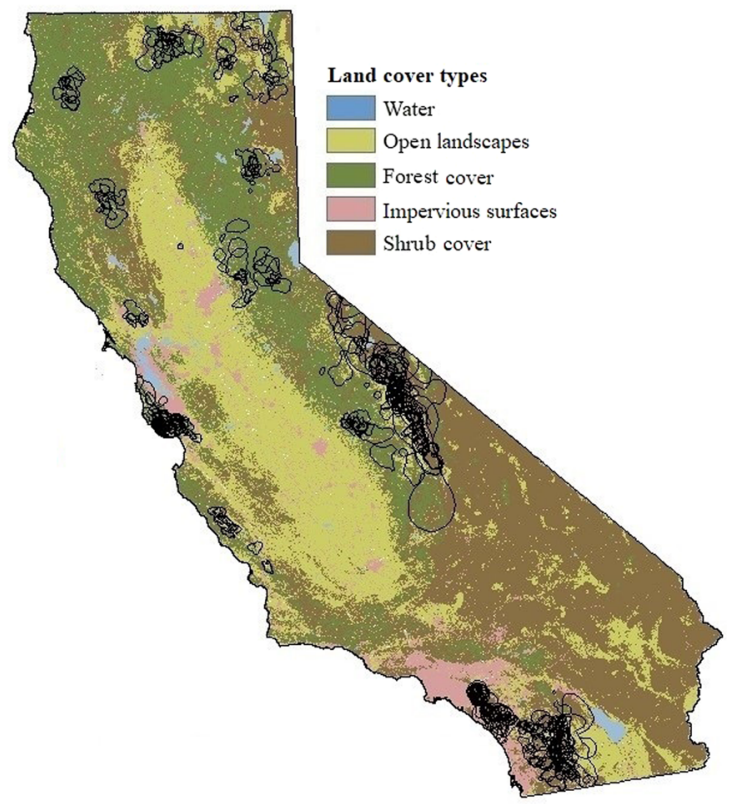

Figure 1. Distribution of home ranges of mountain lions radio-collared in the various project areas that made up the dataset for this study to understand habitat selection of mountain lions in California, USA, 2001-2019. Home ranges are overlaid on a map of the A) ecoregions that make up the state of California and more generally on a map of B) land cover types included in the analyses. 
Table 1. Summary of location data for radio-collared mountain lions by project area in California, USA, from 2001-2019.

\begin{tabular}{lccrlrl}
\hline Project area & $\begin{array}{c}\text { Number of } \\
\text { animals }\end{array}$ & Males & Females & $\begin{array}{c}\text { Number of } \\
\text { locations }\end{array}$ & Platform & Date collected \\
\hline Sutter County & 1 & 0 & 1 & 764 & Globalstar & Jun-Dec 2017 \\
Napa and Sonoma counties & 4 & 1 & 3 & 8,445 & Iridium & 16 Oct-17 Nov \\
Six Rivers National Forest & 7 & 4 & 3 & 11,824 & Iridium & 17 Feb-19 Aug \\
Mendocino National Forest & 7 & 2 & 5 & 13,411 & Globalstar & 10 Jun-12 Dec \\
Plumas National Forest & 7 & 3 & 4 & 9,767 & Globalstar, Iridium & 16 May-17 Nov \\
Sierra National Forest & 8 & 3 & 5 & 22,143 & Globalstar & 14 Apr-17 Sep \\
Central Coast & 9 & 4 & 5 & 14,329 & Iridium & 18 Jan-19 Aug \\
Siskiyou County & 9 & 5 & 4 & 24,605 & Iridium & 17 Jan-18 Jul \\
Tahoe and El Dorado National Forests & 12 & 6 & 6 & 17,937 & Argos & 2 Jan-5 May \\
Modoc National Forest & 14 & 9 & 5 & 39,769 & Iridium & 16 Feb-18 Jun \\
Santa Cruz Mountains & 49 & 28 & 21 & 300,104 & GSM, Globalstar & 9 Mar-17 Oct \\
Mono and Inyo Counties & 54 & 23 & 31 & 77,137 & Argos, Globalstar, Iridium & 2 Mar-19 Aug \\
Santa Ana and Peninsular mountains & 82 & 43 & 39 & 303,265 & Argos, Globalstar, Iridium & 1 Jan-16 Dec \\
Total & 263 & 135 & 128 & 843,500 & & \\
\hline
\end{tabular}

conservation. We predicted that mountain lion habitat selection patterns would demonstrate that much of California is suitable mountain lion habitat and that habitat selection patterns would be consistent across the state.

\section{STUDY AREA}

We collected location data from 2001-2019 on an assortment of private, county, regional, state, federal, and tribal lands across the state of California, which has an area of $423,970 \mathrm{~km}^{2}$ with 8 recognized ecoregions (Sawyer et al. 2009; Fig. 1). Across the areas used by mountain lions, there was substantial variability in the level of human use and development (U.S. Census Bureau 2017; e.g., wilderness areas and locales immediately adjacent to and within large urban population centers). Further, the geographic extent of the dataset represented the diversity of ecoregions, which ranged from Mojave Desert conditions in the Peninsular Range of southern California, to temperate rain forests in the northwestern part of the state. The various ecoregions encompassed large gradients in physical attributes such as elevation (from sea level to $4,000 \mathrm{~m}$; U.S. Geological Survey 2017), seasonal precipitation (13.1-140.9 cm), and temperature $\left(-15-45^{\circ} \mathrm{C}\right)$. Lastly, seasonality varied greatly across the state. Interior areas of California experienced cool summers and cold winters with large amounts of precipitation in the form of snow. Conversely, coastal areas experienced warm summers and cool winters with precipitation in the form of rain (Sawyer et al. 2009). This range of seasonality influenced movement patterns of mule deer (Odocoileus hemionus) and black-tailed deer (O. h. columbianus), the primary prey of mountain lions in California, by inducing long distance migrations in interior areas of the state and local elevational migrations in more coastal areas (Loft and Bleich 2014, Bose et al. 2017).

\section{METHODS}

Each of the project areas identified (Table 1) represents an independent study with objectives unique to that project. Therefore, our efforts represent a compilation of the various independently collected datasets. From 2001 to 2019, we captured subadult and adult mountain lions using a combination of cage traps and trained hounds (Table 1). Upon capture, we anesthetized mountain lions with Telazol $^{\circledR}$ (tiletamine $\mathrm{HCl}$ and zolazepam $\mathrm{HCl}$; Fort Dodge Animal Health, Fort Dodge, IA, USA) or a combination of ketamine and medetomidine or xylazine. Given that CDFW is the state agency in California with wildlife trustee authority, captures led by CDFW personnel were conducted with the approval of a CDFW wildlife veterinarian and under the scope of CDFW's animal care and use policy (CDFW Operations Manual Policy 149). Captures led by non-CDFW personnel (e.g., universities or non-governmental organizations) were conducted under the approval of CDFW (permit numbers SC-011968, SC-007303, SC-002730, SC-009875, and SC-013416) or an affiliated animal care and use committee (University of California, Santa Cruz, protocol number Wilmc1101; University of California, Davis, protocol number 17233). Captured animals weighing $\geq 27.5 \mathrm{~kg}$ received global positioning system (GPS) radio-collars. Global positioning system-collar platform (i.e., GSM, Globalstar, Iridium; Lotek, New Market, ON, Canada; Telonics, Mesa, AZ, USA; Advanced Telemetry Systems, Ishanti, MN, USA; Vectronics Aerospace, Berlin, Germany), and functionality varied within and among specific project areas. Fix rates varied from 4-24 locations/day (Table 1). Metrics of spatial accuracy and fix rate success of GPS locations were not available for all project areas but ranged between $75 \%$ and $97 \%$. The lowest reported location accuracy for any of the project areas was $100 \mathrm{~m}$.

Initially we collated data from 270 individual animals. We excluded data from animals exhibiting space use inconsistent with an established home range (i.e., not demonstrating a central area of use, dispersing) and data from animals with too few locations to determine if they had an established home range (Dellinger et al. 2013). After applying these filters, our dataset consisted of 843,500 locations ( $\overline{\mathrm{x}}=3,207$ locations/individual or 420 days/individual, range $=61-8,656$ locations/individual) for 263 unique individuals (128 females and 135 males). Although most environmental conditions where mountain lions occur in California were represented, the GPS data and number of individuals represented were unevenly distributed across the state's ecoregions (Fig. 1; Table 1). 


\section{Data Analysis}

We developed resource selection functions (RSF) to elucidate habitat selection patterns of mountain lions at the home range and within home range scales, which correspond to Johnson's (1980) second and third orders of selection, respectively. We analyzed home range scale resource selection in a use-availability framework (Manly et al. 2002) wherein we defined use by $95 \%$ adaptive nearest-neighbor convex hull (a-NNCH; Getz et al. 2007) home ranges for each radio-collared mountain lion and available by the circular home ranges distributed across California. More specifically, home range scale habitat selection can be defined as the factors influencing where mountain lions select to establish a home range, whereas within home range scale habitat selection pertains to the usage of various habitat components within the home range (Johnson 1980). Practically speaking, home range scale habitat selection can elucidate where mountain lions are likely to occur on the landscape in general, whereas within home range scale habitat selection can demonstrate what locales are likely to be used more or less than others in areas where mountain lions occur. For the home range scale analyses, we calculated $95 \%$ a-NNCH home ranges for each individual. We used a-NNCHs over other home range estimation methods to aid in identifying home range boundaries (i.e., not wanting to overestimate areas used by individuals); and we used $95 \%$ a-NNCHs rather than $100 \%$ a-NNCHs to exclude any extra-territorial forays that might include any habitat outside of the normal activity patterns of radio-collared individuals (Burdett et al. 2010, Elbroch and Wittmer 2012). We then sampled available resources at the home range scale by randomly generating 2,000 regularly spaced circular home ranges across California that were equal in area to the average mountain lion $95 \%$ a- $\mathrm{NNCH}$ home range (male and female combined; $400 \mathrm{~km}^{2}$ ) derived from the raw GPS data. Although it is unlikely that mountain lions can establish a home range in all areas of California, it is notable that mountain lions can establish home ranges in areas previously considered unsuitable such as the Sacramento Valley (McClanahan et al. 2017), near downtown Los Angeles (Benson et al. 2016), and the Mojave Desert (Dellinger et al. 2019).

For the within home range scale analyses, we separated our GPS data into 2 seasons: winter (Oct-Mar), and summer (Apr-Sep). For each season we calculated individual $95 \%$ a-NNCH home ranges resulting in 233 and 214 individuals represented in winter and summer, respectively. We used individual GPS locations within these $95 \%$ seasonal a-NNCH home ranges (winter $=436,200$ locations, summer $=407,300$ locations) to determine mountain lion resource selection within their respective seasonal home ranges. We sampled available resources for each individual by generating regularly spaced points $100 \mathrm{~m}$ apart within their respective $95 \%$ seasonal a-NNCHs (Benson 2013). This resulted in ratios of $1: 10$ and $1: 12$ for use and available locations in winter and summer, respectively (Benson 2013).

We examined a suite of biotic and abiotic environmental variables extracted from various sources to determine factors associated with mountain lion habitat selection in California at home range and within home range scales (Table 2). Abiotic variables included elevation (m), slope (\%), terrain ruggedness (index), distance to secondary road (e.g., dirt roads; $\mathrm{m}$ ), and distance to year-round water $(\mathrm{m})$. Biotic variables included human density (per $\mathrm{km}^{2}$ ), distance to forest cover (m), distance to open landscapes (m), distance to shrub cover $(\mathrm{m})$, and distance to impervious surfaces (m; e.g., concrete or asphalt). These variables were on a continuous scale, and were included to index prey habitat, mountain lion hunting style, and anthropogenic mortality risk. We also included a biotic variable, deer prevalence, which we used only for our home range scale analysis. We derived this variable from long-term population monitoring data collected by the CDFW. Deer prevalence was categorical; options included year-round presence, summer range only, winter range only, and limited presence (i.e., intermittently used). We chose all variables because they influenced mountain lion habitat selection in California (Pierce et al. 1999, Burdett et al. 2010, Wilmers et al. 2013, Benson et al. 2016, Dellinger et al. 2018). We limited land cover-derived variables to 4 options because of the diversity of land cover across California (i.e., we did not want to overparameterize the models) and because some land covers were only present regionally (i.e., not available to animals in some areas). Thus, we used forest cover, open landscapes, shrub cover, and impervious surfaces given that these land covers were generally present across the state in some variation. We analyzed variables at a $30 \times 30-\mathrm{m}$ and $1 \times 1-\mathrm{km}$ resolution for within home range and home range scale analyses, respectively. We assessed distance to various

Table 2. Predictor variables used in analyses of habitat selection of mountain lions throughout California, USA, from 2001-2019.

\begin{tabular}{lccll}
\hline Variable & Units & Resolution $\left.\mathbf{( m}^{\mathbf{2}}\right)$ & Order & \\
\hline Elevation & $\mathrm{m}$ & 30 & Soth & U.S. Geological Survey (2017) \\
Slope & $\circ$ & 30 & Both & Derived from Elevation \\
Terrain ruggedness & index & 30 & Both & Derived from Elevation \\
Human density & humans $/ \mathrm{km}^{2}$ & 30 & Both & U.S. Census Bureau (2017) \\
Deer prevalence & index & 1,000 & 2 & California Department of Fish and Wildlife (2016) \\
Distance to forest cover & $\mathrm{m}$ & 30 & Both & Sawyer et al. (2009) \\
Distance to open landscapes & $\mathrm{m}$ & 30 & Both & Sawyer et al. (2009) \\
Distance to impervious surfaces & $\mathrm{m}$ & 30 & Both & National Land Cover Database (2011) \\
Distance to shrub cover & $\mathrm{m}$ & 30 & Both & Sawyer et al. (2009) \\
Distance to secondary road & $\mathrm{m}$ & 30 & Both & U.S. Census Bureau (2017) \\
Distance to year-round water & $\mathrm{m}$ & 30 & Both & U.S. Geological Survey (2017) \\
\hline
\end{tabular}


abiotic and biotic variables using a Euclidean distance analysis (EDA) framework (Benson 2013). We standardized all continuous variables by subtracting the mean from each value and then divided by the standard deviation (i.e., we placed continuous variables on the same scale) to render coefficient estimates derived from these variables easier to interpret and comparable to each other. We then intersected use and available data for both scales with spatial raster layers of each variable mentioned above. We averaged variables across each polygon (i.e., use $=95 \%$ a-NNCH; available $=$ circular home ranges) for home range scale analyses. For within home range scale analyses, we assigned use and available locations the exact values of the pixel of the corresponding variable. Given that some of these variables (e.g., human density and distance to secondary road) likely changed over time during accumulation of our dataset, we intersected use and available data for a given year with the raster layer depicting that variable of interest in the same year.

Using logistic regression, we assessed support for including quadratic variables at both spatial scales, to help identify potential thresholds in animal relationships to various environmental characteristics. After assessing quadratic relationships, we checked for collinearity among predictor variables at both spatial scales and removed those with high correlations $(|r|>0.60)$. When 2 variables were correlated at or beyond this threshold, we selected the more significant variable when modeled on its own against use-availability data using logistic regression. Following examination of quadratic and collinearity relationships, we then used binominal logistic regression to build RSFs at the home range and within home range scale using fixed and mixed effects (Boyce et al. 2002, Manly et al. 2002). Given that GPS fix rate success was $<100 \%$, we accounted for the influence of GPS fix success on RSF estimates by including weights for detection depending on land cover (Nielson et al. 2009). Specifically, we used a fixed-effects model at the home range scale because we assessed differences in use and availability across mountain lion home ranges instead of based on the different mountain lion project areas that contributed data (Table 1; Holbrook et al. 2017). We used a mixed-effects model at the within home range scale to build seasonal RSFs because we assessed differences in use and availability for different mountain lion project areas. We included a random effect for project area to account for unequal sampling effort among project areas and potential regional differences in mountain lion habitat selection due to ecoregion (Grigione et al. 2002).

Though logistic regression is common for estimating an RSF for studies of wildlife habitat selection (Morris et al. 2016), there are assumptions and considerations that must be acknowledged. First, it is assumed that the resulting relative probability of use derived from an RSF created using a logistic regression is proportional to the actual probability of use derived from a resource selection probability function (Keating and Cherry 2004). Johnson et al. (2006) demonstrated that although this assumption is of concern, it likely does not render the RSFs created via logistic regression useless. Second, a use-availability dataset such as ours can suffer from overlap or contamination wherein locations designated as available to be used might also be locations that were actually used (Keating and Cherry 2004). Coefficients of RSFs, however, were robust to contamination except in extreme cases wherein overlap was $>50 \%$ and $<20 \%$ is likely a more realistic amount of contamination of GPS radio-collar data (Johnson et al. 2006). Next, autocorrelation of GPS locations can underestimate the variance associated with the coefficient estimates, but not the coefficient estimates themselves, and increase the chance of a type I error (Boyce 2006). We attempted to control for autocorrelation among animals by not using data of simultaneously radio-collared females and dependent young. Further, we attempted to account for type I errors arising from autocorrelation by focusing interpretation of results on selecting the most parsimonious model and not on statistical significance of individual variables within RSF models (Boyce 2006). Lastly, we considered location error, which was most likely to arise via Argos GPS platforms. There were 3 projects that used this GPS platform to some extent (Table 1). As mentioned above, the lowest reported location accuracy for any of the project areas was $100 \mathrm{~m}$ (project in the Tahoe and El Dorado National Forests), which was larger than the smallest pixel size we used $(30 \times 30 \mathrm{~m})$. Most $(99 \%)$ of the locations in this project had a location accuracy of $<30 \mathrm{~m}$ (Orlando 2008). The project in Mono and Inyo counties relied primarily on Globalstar or Iridium platforms. Further, approximately 84\% of the GPS locations in the Santa Ana and Peninsular mountains were from a Globalstar or Iridium platform or an Argos platform with 3-dimensioinal fixes, which generally have location errors $<30 \mathrm{~m}$. Given these aspects of location error, most of our GPS data had location error that was less than our smallest pixel size and data with location error $>30 \mathrm{~m}$ likely had little effect on our analyses.

We randomly selected $75 \%$ of the use and available home range scale data to build a global fixed-effects RSF and 75\% of the use and available within home range scale data to build seasonal global mixed-effects RSFs. We withheld the remaining $25 \%$ of the data to evaluate the fit of model coefficient estimates. We used Akaike's Information Criterion corrected for small sample sizes $\left(\mathrm{AIC}_{c}\right)$ to determine the most parsimonious models (i.e., home range scale, summer within home range scale, and winter within home range scale; Burnham and Anderson 2002) from the global models and all possible subsets. The most parsimonious models were those with the lowest $\Delta \mathrm{AIC}_{c}$ and highest $\mathrm{AIC}_{c}$ weight (Arnold 2010). Resource selection function outputs from the most parsimonious model yielded coefficient estimates that we used to understand mountain lion relative probability of habitat selection along a gradient of variables (Boyce et al. 2002).

We evaluated fit of the coefficient estimates of our most parsimonious RSFs using the $25 \%$ of use and available data excluded from the model building process. This cross-validation method, shown to be appropriate for use-availability RSF models (Johnson et al. 2006), involved first projecting 
coefficient estimates of each most parsimonious RSF in a geographic information system (GIS) using the logit link function. This resulted in raster pixel values ranging from 0 to 1 . We reclassified these values into 10 equally sized ordinal classes using quantiles ranging from 1 to 10 (e.g., $0.0-0.1$ becomes 1 ), which depicted low (i.e., 1) to high (i.e., 10) relative probability of use for mountain lions (Holbrook et al. 2017). We counted the number of used locations in the withheld data that fell in each ordinal class by overlaying the withheld data onto the projected RSF. We then generated expected number of used locations in each ordinal class based on number and average value of pixels in each ordinal class (Johnson et al. 2006). Lastly, we used Spearman rank correlations $\left(r_{\mathrm{s}}\right)$ to assess association between observed and expected number of used locations in each ordinal class. A strong Spearman rank correlation coefficient indicated a model with good ability to predict mountain lion relative probability of habitat selection (Johnson et al. 2006, Dellinger et al. 2013). We conducted cross-validation separately for each of the 3 sets of most parsimonious RSF coefficient estimates.

As a last step, we estimated the amount of suitable habitat available to mountain lions in California. This requires an understanding of the mechanisms explaining selection at the home range scale and selection within home ranges that give rise to the home range scale distribution (Holbrook et al. 2017). Following determination of whether each set of most parsimonious RSF coefficient estimates had good ability to predict mountain lion relative probability of habitat selection, we estimated the cut-point probability of each model that captured $90 \%$ of the observed mountain lion home ranges (i.e., second order) or locations (i.e., third order; Johnson 1980, Hebblewhite et al. 2011), respectively. We used this cutpoint to reclassify areas across California depicted in the raster layers mentioned above as either unsuitable or suitable with a relative probability of use above the cutpoint (Hebblewhite et al. 2014, Holbrook et al. 2017). We developed multiscale seasonal habitat maps by multiplying our home range scale raster layer separately with each of the 2 seasonal within home range scale raster layers. The result was separate summer and winter multiscale habitat maps. Pixel values $>0$ in these multiscale habitat maps represented habitat above the cut-point for the home range scale and both within home range scale RSF models. Thus, we used number of pixels in each multiscale habitat map to estimate amount of suitable habitat available to mountain lions in California in summer and winter, respectively. Lastly, we overlaid protected lands (e.g., public lands and private lands with conservation easements; California Protected Areas Database 2017) onto the multiscale habitat maps to determine amount of suitable habitat likely to remain undeveloped.

We used Program R version 3.4.3 (R Core Team 2017) and associated packages MuMin (Barton 2019), lme4 (Bates et al. 2015), and agricolae (Mendiburu 2019) for all statistical analyses and data management (e.g., deriving home ranges). We used ArcView GIS version 10.3.1 (Esri, Redlands, CA, USA) and Geospatial Modelling Environment version 0.7.4.0
Table 3. Comparison of change in Akaike's Information Criterion corrected for small sample sizes $\left(\Delta \mathrm{AIC}_{c}\right), \mathrm{AIC}_{c}$ weights, and number of parameters $(K)$ of the most parsimonious resource selection function models for understanding home range scale (i.e., second-order resource selection; Johnson 1980) habitat selection of mountain lions throughout California, USA, from 2001-2019. The table below only represents models with an $\mathrm{AIC}_{c}$ weight $>0.05$ and $\Delta \mathrm{AIC}_{c}<5$.

\begin{tabular}{|c|c|c|c|}
\hline Model $^{a}$ & $\Delta \mathrm{AIC}_{c}$ & Weight & $K$ \\
\hline $\begin{array}{l}\text { Elevation }+ \text { slope }+ \text { slope }^{2}+\text { open }+ \text { open }^{2}+ \\
\text { forest }+ \text { forest }^{2}+\text { shrub }+ \text { road }+ \text { road }^{2}+ \\
\text { deer limited }+ \text { deer year-round }\end{array}$ & 0.00 & 0.38 & 12 \\
\hline+ deer winter & 1.55 & 0.18 & 13 \\
\hline$+\operatorname{shrub}^{2}$ & 1.85 & 0.15 & 13 \\
\hline + water & 2.35 & 0.12 & 13 \\
\hline + human & 2.65 & 0.10 & 13 \\
\hline$+\operatorname{shrub}^{2}+$ deer winter & 3.45 & 0.07 & 14 \\
\hline
\end{tabular}

a All models include an intercept. Covariates included elevation; slope; distance to open landscapes (open), forest cover (forest), shrub cover (shrub), secondary roads (road), and year-round water (water); limited deer presence (deer limited; intermittently used); year-round deer presence (deer year-round); winter deer presence (deer winter); and human density (human).

b All models included covariates elevation, slope, slope ${ }^{2}$, open, open ${ }^{2}$, forest, forest ${ }^{2}$, shrub, road, roads ${ }^{2}$, deer limited, and deer year-round. Only covariates not represented in all models are detailed for models subsequent to the most parsimonious model.

(Beyer 2015) for spatial analyses and visual representation of data and results.

\section{RESULTS}

Mountain lions selected for increasing elevation, deer prevalence, distance to open landscapes, and intermediate slopes at the home range scale (Tables 3 and 4). Further, mountain lions selected areas closer to forest cover, shrub cover, and secondary roads relative to average available distances at the home range scale (Table 4). Variables included in our most parsimonious RSF models varied between spatial scales but not seasons. At the home range scale there were 3 models with $\Delta \mathrm{AIC}_{c} \leq 2$, but the evidence ratios derived from comparing the $\mathrm{AIC}_{c}$ weight of the most parsimonious model with the second and third models was 2.1 and 2.5 , respectively, allowing one to conclude that the most parsimonious model was the best fitting model (Table 3). The most parsimonious

Table 4. The most parsimonious resource selection function (RSF) model for understanding home range scale mountain lion habitat selection throughout California, USA, from 2001-2019. Coefficient estimates ( $\beta$ ), standard error (SE), and $P$-value are presented for each variable present in the most parsimonious RSF model.

\begin{tabular}{|c|c|c|c|}
\hline Variable & $\beta$ & SE & $P$ \\
\hline Elevation & 0.796 & 0.153 & $<0.001$ \\
\hline Slope & 1.020 & 0.272 & $<0.001$ \\
\hline Slope $^{2}$ & -0.591 & 0.264 & 0.025 \\
\hline Distance to open landscapes & 0.476 & 0.249 & 0.056 \\
\hline Distance to open landscapes ${ }^{2}$ & -1.884 & 0.469 & $<0.001$ \\
\hline Distance to forest cover & -3.727 & 2.655 & 0.161 \\
\hline Distance to forest cover ${ }^{2}$ & -8.865 & 5.013 & 0.077 \\
\hline Distance to shrub cover & -4.390 & 2.301 & 0.056 \\
\hline Distance to secondary road & -2.093 & 0.362 & $<0.001$ \\
\hline Distance to secondary road ${ }^{2}$ & 0.308 & 0.069 & $<0.001$ \\
\hline Deer presence limited & -1.741 & 0.476 & $<0.001$ \\
\hline Deer present year-round & 1.051 & 0.169 & $<0.001$ \\
\hline
\end{tabular}



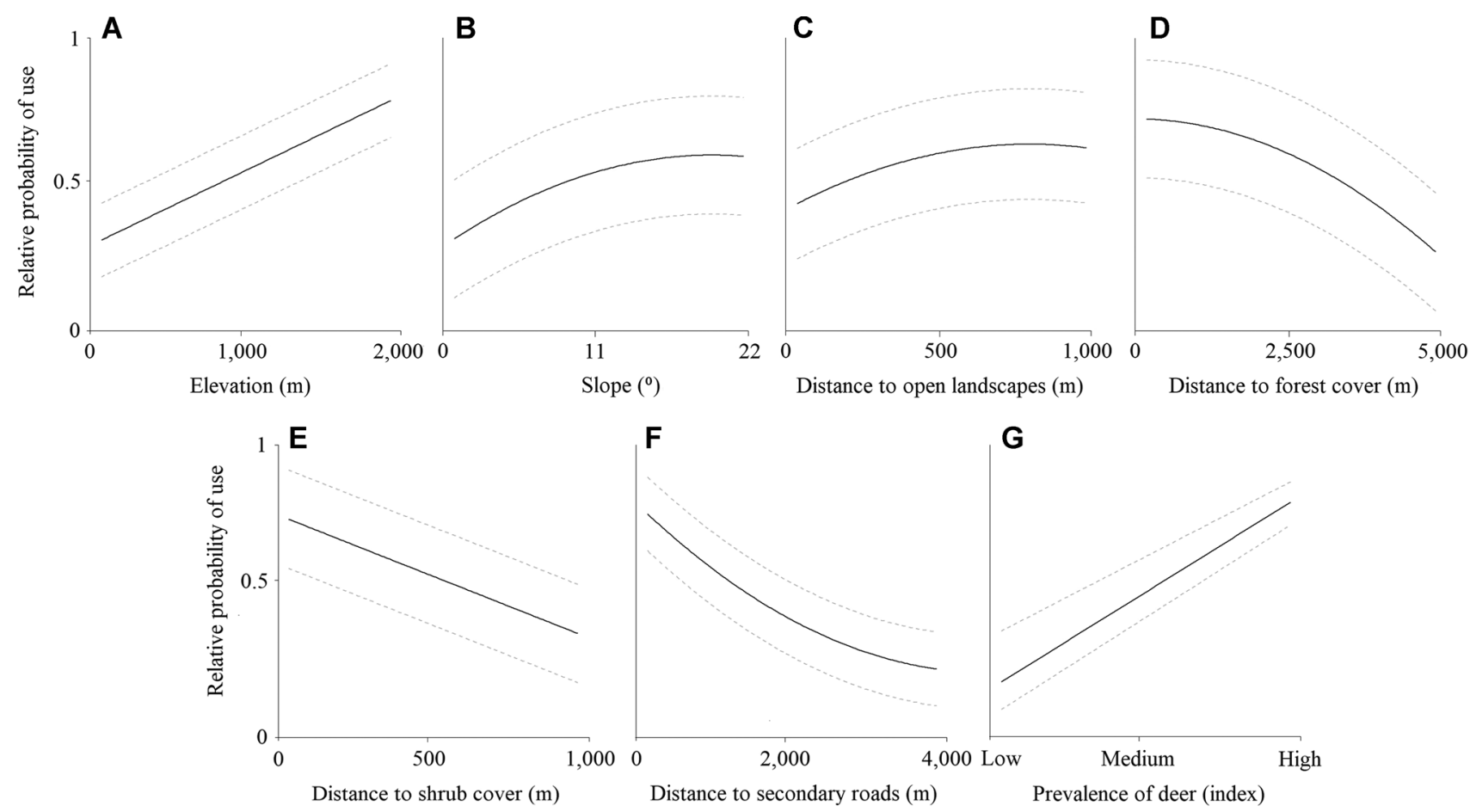

Figure 2. Mountain lion relative probability of use (solid lines) and associated $95 \%$ confidence intervals (dashed lines) of variables as it relates to home range scale (second order; Johnson 1980) habitat selection in California, USA, 2001-2019. We derived relative probabilities from coefficient estimates from the most parsimonious home range scale resource selection function in a use and available framework.

home range scale RSF included coefficient estimates of all linear (i.e., non-quadratic) variables (Table 2) except human density, terrain ruggedness, distance to impervious surfaces, and distance to year-round water. Terrain ruggedness and distance to impervious surfaces were not included because of high correlation $(>0.60)$ with slope and distance to secondary road, respectively. Slope and distance to secondary road performed better than terrain ruggedness and distance to impervious surfaces when compared to home range scale use-availability data in a logistic regression framework (i.e., higher $R^{2}$ value). Further, the most parsimonious home range scale RSF included coefficient estimates for quadratic variables of slope, distance to open landscapes, distance to forest cover, and distance to secondary road (Table 4). Increasing elevation (Fig. 2A), distance to open landscapes (Fig. 2C), and deer prevalence (Fig. 2G) had a positive effect on mountain lion relative probability of habitat selection at the home range scale. At low slopes, mountain lions selected for increasing slope; however, mountain lions avoided increasing slopes as slopes increased beyond $21^{\circ}$ (Fig. 2B). Mountain lions selected for areas close to shrubs and areas within and adjacent to forest cover and avoided areas $>2 \mathrm{~km}$ from forest cover (Fig. 2D,E). Further, mountain lions selected for areas near secondary roads (Fig. 2F). Spearman rank correlations from our cross-validation indicated our most parsimonious home range scale RSF had good predictive ability $\left(r_{\mathrm{s}}=0.90, P<0.001\right)$. The $90 \%$ cut-point for our most-parsimonious home range scale RSF was 0.08 and identified $127,319 \mathrm{~km}^{2}$ of suitable mountain lion habitat across California at the home range scale (Fig. 3A).
The top summer and winter within home range scale RSFs included all linear variables and associated quadratic terms except terrain ruggedness and distance to impervious surfaces, which were omitted because of high correlation with slope and elevation, respectively, at this scale (Table 5). The most parsimonious RSFs for each season had $\mathrm{AIC}_{c}$ weights of $>0.99$ and thus were the only models we considered in further analysis. The random effect for project area had a correlation of 0.071 and 0.105 for winter and summer, respectively. Thus, project area accounted for more variability in mountain lion relative probability of habitat selection patterns in summer compared to winter. Broadly speaking, these correlation values demonstrate the degree to which animals in the same project area exhibited similar habitat selection patterns. All variables were consistently selected or avoided during both seasons (i.e., the signs of the coefficients did not change between seasons; Table 5). Mountain lions avoided areas of exceedingly high elevation (Fig. 4A), close to open landscapes (Fig. 4C), and with greater human density (Fig. $4 \mathrm{H}$ ) in both seasons. At low slopes, mountain lions again selected for increasing slope; however, mountain lions avoided increasing slopes as slopes increased beyond $20^{\circ}$ (Fig. 4B). Mountain lions selected for areas close to secondary roads and avoided areas $>300 \mathrm{~m}$ from secondary roads (Fig. 4F). Further, mountain lions again selected for areas within and adjacent to forest cover and shrub cover (Fig. 4D,E). Mountain lions also selected for areas close to secondary roads and year-round water (Fig. 4F,G). Though increasing values of some distance variables (e.g., distance to forest cover) had initial negative effects on mountain lion relative probability of selection and 

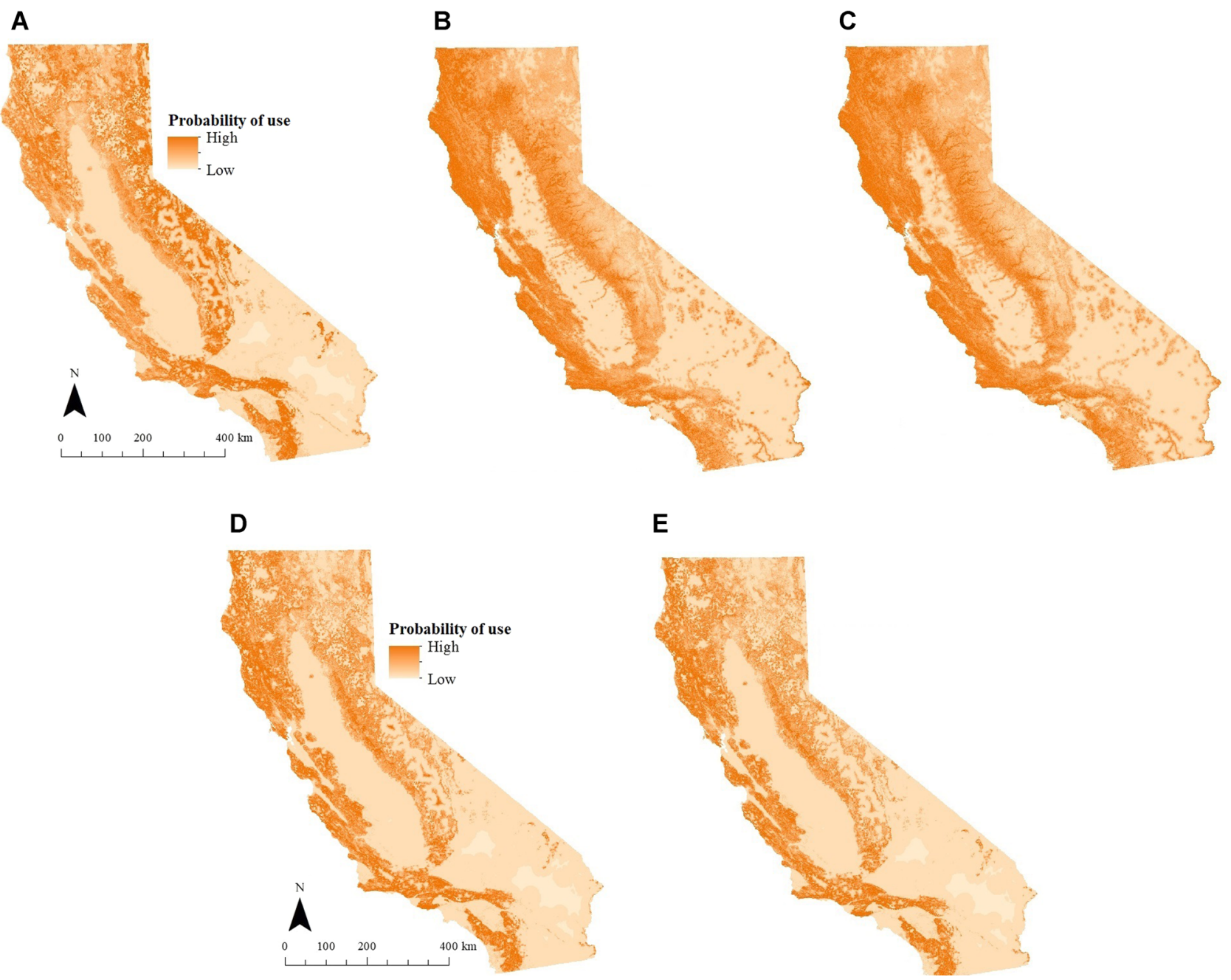

Figure 3. Spatial representation of the most parsimonious resource selection functions (RSFs) for understanding A) mountain lion habitat selection at the home range scale, B) within home range scale in summer, and C) within home range scale in winter in California, USA, 2001-2019. We created the integrated mountain lion summer habitat selection map (D) by multiplying the most parsimonious home range scale and within home range scale summer RSFs, respectively. We created the integrated mountain lion winter habitat selection map (E) by multiplying the most parsimonious home range scale and within home range scale winter RSFs, respectively. Relative probability of use in these figures ranges from low ( 0 or $0 \%$ relative probability of use) to high (1 or $100 \%$ relative probability of use).

then positive effects on mountain lion relative probability of selection at greater distances, these higher distances exceeded the average distance to the variable of interest (e.g., forest cover: $\bar{x}=3.5 \pm 6.4[\mathrm{SD}] \mathrm{km})$. Thus, positive effects of high distance values on mountain lion relative probability of selection are likely more a function of the modeling process than any real biological process. Spearman rank correlations from our cross-validation indicated our most parsimonious summer and winter within home range scale RSFs each had good predictive ability (summer: $r_{\mathrm{s}}=0.84$, $P<0.001$; winter: $r_{\mathrm{s}}=0.97, P<0.001$ ). The $90 \%$ cut-points for our most parsimonious summer and winter within home range scale RSFs were 0.028 and 0.039 , respectively. The seasonal RSFs identified $218,892 \mathrm{~km}^{2}$ and $214,128 \mathrm{~km}^{2}$ of suitable mountain lion habitat across California at the within home range scale in summer (Fig. 3B) and winter (Fig. 3C), respectively.

The multiscale habitat maps revealed $170,085 \mathrm{~km}^{2}$ and $165,350 \mathrm{~km}^{2}$ of habitat across California that can be expected to be used by mountain lions in summer (Fig. 3D) and winter (Fig. 3E), respectively (i.e., $40 \%$ and $39 \%$ of the state). Of the available suitable habitat revealed in the multiscale habitat maps, approximately $50 \%\left(84,858 \mathrm{~km}^{2}\right.$ in summer and $83,403 \mathrm{~km}^{2}$ in winter) existed on protected lands or lands likely to remain undeveloped.

\section{DISCUSSION}

We quantified mountain lion habitat selection using a range of environmental variables across California and GPS-collar data collected from all over the state during an 18-year period (Table 1). We demonstrated that 39-40\% (dependent on season) of California's land mass consists of habitat that we would expect mountain lions to use to some extent, though relative levels of expected use, and possibly density, vary substantially across California (Pierce et al. 1999, Burdett et al. 2010, Wilmers et al. 2013, Zeller et al. 2017, Dellinger et al. 2018; Fig. 3A). Although we identified suitable mountain lion habitat in all ecoregions, the 
Table 5. The most parsimonious resource selection function (RSF) models for understanding within home range scale (i.e., third-order resource selection; Johnson 1980) habitat selection of mountain lions throughout California, USA, in winter (Oct-Mar) and summer (Apr-Sep) from 2001-2019. Given that each of these seasonal RSF models had an Akaike weight of $>0.99$, we only display the top model for each season. Coefficient estimates $(\beta)$, standard error (SE), and $P$-value are presented for each fixed variable present in the most parsimonious seasonal RSF models. Variance (and SD) for the random variable project area were $0.251(0.501)$ and $0.385(0.620)$ in winter and summer, respectively. Lastly, correlation for the random variable project area was 0.071 and 0.105 in winter and summer, respectively.

\begin{tabular}{|c|c|c|c|c|c|c|}
\hline \multirow[b]{2}{*}{ Fixed variable } & \multicolumn{3}{|c|}{ Winter } & \multicolumn{3}{|c|}{ Summer } \\
\hline & $\beta$ & SE & $P$ & $\beta$ & SE & $P$ \\
\hline Elevation & -0.673 & 0.005 & $<0.001$ & -0.630 & 0.006 & $<0.001$ \\
\hline Elevation $^{2}$ & -0.013 & 0.003 & $<0.001$ & 0.104 & 0.002 & $<0.001$ \\
\hline Slope $^{2}$ & -0.288 & 0.003 & $<0.001$ & -0.216 & 0.003 & $<0.001$ \\
\hline Distance to open landscapes & 0.036 & 0.005 & $<0.001$ & 0.237 & 0.006 & $<0.001$ \\
\hline Distance to open landscapes ${ }^{2}$ & -0.147 & 0.004 & $<0.001$ & -0.236 & 0.005 & $<0.001$ \\
\hline Distance to shrub cover & -0.777 & 0.049 & $<0.001$ & -1.649 & 0.049 & $<0.001$ \\
\hline Distance to shrub cover ${ }^{2}$ & 7.898 & 0.119 & $<0.001$ & 6.559 & 0.133 & $<0.001$ \\
\hline Distance to secondary road & -0.069 & 0.007 & $<0.001$ & -0.041 & 0.007 & $<0.001$ \\
\hline Distance to secondary road ${ }^{2}$ & -0.079 & 0.004 & $<0.001$ & -0.036 & 0.002 & $<0.001$ \\
\hline Distance to year-round water ${ }^{\mathrm{a}}$ & -0.443 & 0.008 & $<0.001$ & -0.471 & 0.008 & $<0.001$ \\
\hline Distance to year-round water ${ }^{2}$ & 0.121 & 0.002 & $<0.001$ & -0.036 & 0.002 & $<0.001$ \\
\hline
\end{tabular}

${ }^{a}$ No significant difference between seasons.

amount in each ecoregion varied widely. We verified a suite of environmental variables, and 1 human-related variable (i.e., secondary roads, which foster early successional plant communities used by deer), were associated with mountain lion habitat selection at the home range scale (Table 4). We were unable to quantify the influence of human density on mountain lion habitat selection at the home range scale because this variable did not contribute significantly to our modeling results for mountain lion habitat selection at this scale, but our results generally agree with previous research demonstrating that mountain lions select for areas of increased topography, cover, and deer prevalence, and use
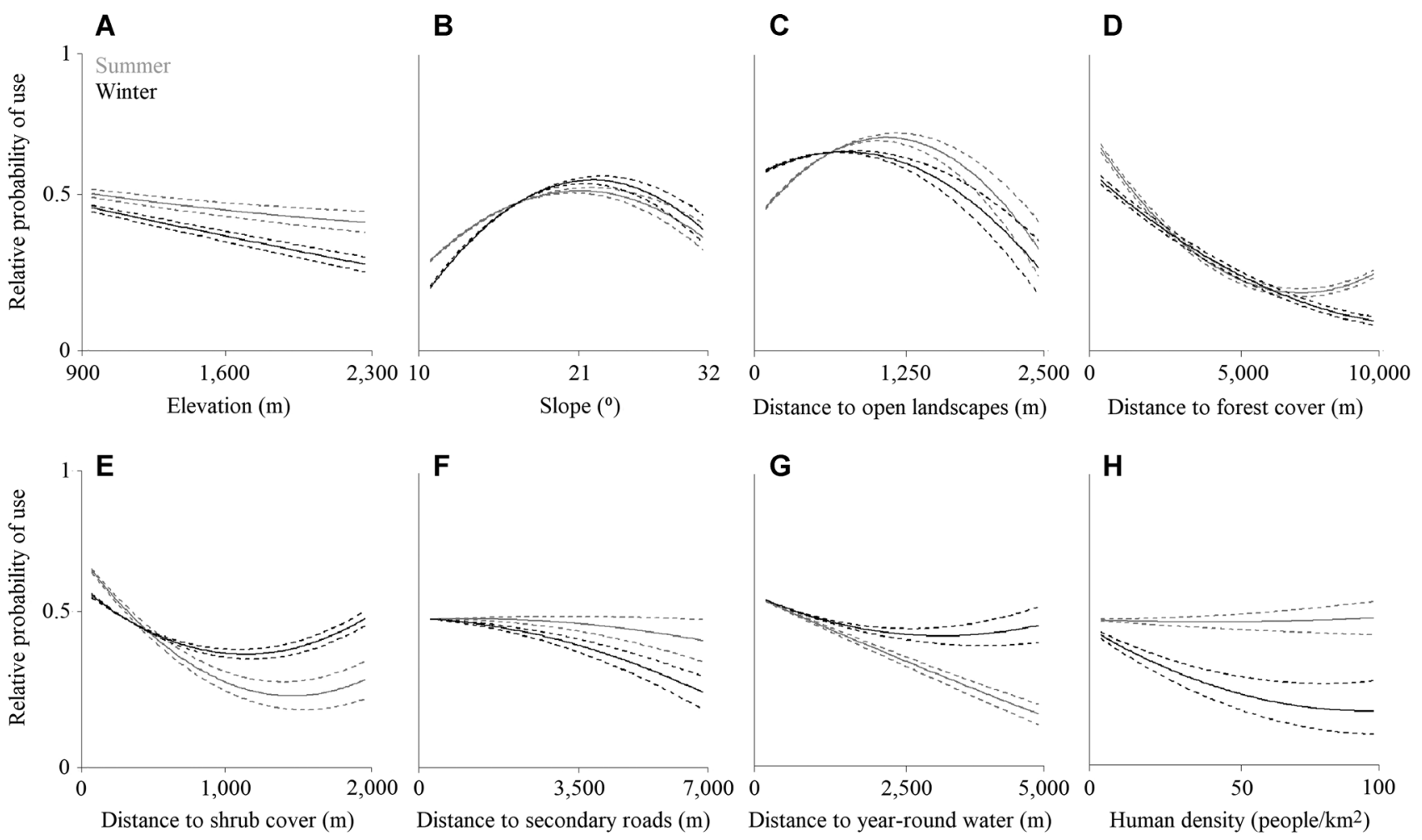

Figure 4. Mountain lion relative probability of use (solid lines) and associated $95 \%$ confidence intervals (dashed lines) of variables as it relates to within home range scale (third order; Johnson 1980) habitat selection in California, USA, 2001-2019, in summer (gray) and winter (black), respectively. We derived relative probabilities from coefficient estimates from the most parsimonious within home range scale resource selection functions for each season in a use-available framework. 
secondary roads when available (Grigione et al. 2002, Wilmers et al. 2013, Blake and Gese 2016, Dellinger et al. 2018). In general, mountain lion habitat selection in relation to these variables point to prey presence and vulnerability to predation as the primary drivers predicting mountain lion habitat (Cougar Management Guidelines Working Group 2005).

We found seasonality in mountain lion habitat selection within home ranges (Fig. 3B,C) and there was significant difference between seasons with respect to selection patterns of the variables examined (Fig. 4; Table 5). Mountain lions selected areas with lower elevations and closer to secondary roads in winter than summer. Though previous studies have reported seasonality in mountain lion habitat selection in California, stemming from snow accumulation and subsequent deer migration (Pierce et al. 1999, Dellinger et al. 2018), our statewide analysis included these areas in addition to areas where little seasonality exists in mountain lion habitat selection patterns. The combined datasets could have diluted the seasonality of habitat selection in the more temperate areas of California. Further, we determined that project area accounted for a large amount of variability in habitat selection in summer (10.5\%) and winter (7.1\%). This possibly demonstrates that habitat selection can vary in mountain lions from one ecoregion to the next within seasons, in addition to between seasons within an ecoregion (Pierce et al. 1999, Grigione et al. 2002, Elbroch and Wittmer 2012, Wilmers et al. 2013, Dellinger et al. 2018). For example, coastal areas experience moderate climate conditions year-round compared to more interior areas where snow can accumulate seasonally. Further, deer in the coastal areas tend to migrate shorter distances than deer in more interior areas of California, stemming from the varied effects of forage desiccation and snow accumulation (Loft and Bleich 2014). It is likely that these seasonal differences, and associated seasonal movement patterns of local deer populations, are what are influencing differences in habitat selection among ecoregions. We acknowledge that our individual project area datasets varied widely in size and, although we tried to account for this via a random effect for project area, this variation in dataset size and distribution potentially influenced our habitat selection results across California.

When selecting a home range (i.e., second-order selection), mountain lions in California appeared to choose areas with the primary purpose of meeting their energetic demands. Deer are the primary prey of mountain lions throughout the state (Pierce et al. 1999, Smith et al. 2015, Benson et al. 2016, Dellinger et al. 2018) and areas with relatively high prevalence of deer were selected (Fig. 2G); they also selected areas of complex topography (Fig. 2B) and vegetative cover (Fig. 2C-E), which facilitates hunting efficiency (Blake and Gese 2016). Preference for steep slopes was limited however, indicated by intermediate slopes having the highest relative probability of use in the home range scale RSF. This finding suggests that in areas of California where small populations of bighorn sheep are present and predation is a concern, predation should be less likely to occur where bighorn sheep have access to escape terrain (slopes $>27^{\circ}$; Hamel and Cote 2007).

After selecting a home range, further choices (i.e., thirdorder selection) of habitat selection by mountain lions were constrained by previous decisions. This can lead to divergent responses to the same variable at differing spatial scales. For example, as mentioned above, selection for increasing elevation at the home range scale was likely in part necessitated because mountain lions seek out complex topography for aiding hunting efficiency (Blake and Gese 2016). Mountain lions also potentially selected for increasing elevation at the home range scale because elevation is negatively correlated with human development. Conversely, mountain lions showed decreasing selection for elevation at the within home range scale (Fig. 4). This is likely because continual increases in elevation (especially in the Sierra Nevada) inevitably lead to areas with harsher climates and less prey (at least seasonally). Further, human density was negatively associated with habitat selection at the within home range scale (Fig. 4). Thus, mountain lions consider areas of human activity and attempt to avoid them when moving about their home range (Wilmers et al. 2013, Smith et al. 2015, Benson et al. 2016). This may enable mountain lions to have a cosmopolitan distribution, occurring in areas of wideranging human densities.

Mountain lions are wide ranging elusive animals that cannot be easily surveyed and monitored (Hornocker and Negri 2010). Understanding habitat selection is a viable way of identifying suitable habitat and subsequently defining populations for which all desirable management actions will be based (Cougar Management Guidelines Working Group 2005). The primary management action expected of most wildlife agencies relates to estimating status and trend of populations through time. Recent developments in statistics and wildlife monitoring techniques suggest using a priori information on habitat selection patterns of the species of interest to inform sampling design (Royle et al. 2013). Such an approach can result in more robust wildlife population density estimates compared to sampling designs not informed by habitat selection patterns (Long et al. 2012, Proffitt et al. 2015). In California, state wildlife managers have little knowledge of number and trend of mountain lion populations across the state. This is partly due to costs associated with traditionally accepted methods of estimating mountain lion populations (i.e., radio-collaring; Beausoleil et al. 2013). Our integrated statewide habitat selection maps, combined with recent genetic analyses (Gustafson et al. 2019), can allow state wildlife managers to define mountain lion populations across California (Warren et al. 2016) and then, again relying on our statewide habitat selection models, implement more cost-effective sampling protocols when deriving robust statewide abundance and regional population estimates for mountain lions across California (Davidson et al. 2014). This would reduce the need for invasive techniques such as radio-collaring to estimate mountain lion population density and trend.

Apart from population monitoring and estimation of abundance, most wildlife managers deal with carnivores, 
including mountain lions, from the perspective of understanding predation on big game species (Hurley et al. 2011, Forrester and Wittmer 2013). Given the unique status of mountain lions in California as a specially protected species, any attempts to mediate effects of mountain lions on big game species, except federally listed mountain sheep species (California Fish and Game Commission 2018), must be done using methods other than lethal population control. An understanding of habitat selection patterns can help wildlife managers mediate effects of mountain lions on big game species. For example, researchers have reported mountain lions affecting already declining pronghorn (Antilocapra americana) herds in northeastern California. Juniper (Juniperus spp.) encroachment into pronghorn habitat in northeastern California is thought to facilitate mountain lion access to pronghorn via stalking cover into the relatively open sagebrush (Artemisia spp.) landscapes typically occupied by the pronghorn (Hudgens et al. 2016). Using our results and an understanding of pronghorn distribution, targeted habitat treatments (i.e., juniper removal) in California could restrict mountain lion access to pronghorn and thus potentially reduce effects of predation. Similar recommendations have been made to reduce mountain lion predation on elk (Cervus canadensis; Lehman et al. 2017) and black-tailed deer (Odocoileus hemionus columbianus; Bose et al. 2018). Thus, in some instances wildlife managers in California could influence levels of mountain lion predation on socially and economically important big game species via manipulation of the habitat within which the predator and prey interact rather than lethally removing mountain lions to achieve decreased predation on big game (Bose et al. 2018).

A previous estimate of suitable mountain lion habitat in California using an expert opinion approach reported $170,486 \mathrm{~km}^{2}$ of moderately to highly suitable habitat (Torres et al. 1996), slightly higher than our integrated summer habitat estimate of $170,085 \mathrm{~km}^{2}$. The similarity between these estimates is noteworthy given the growth of the human population in California by approximately $25 \%$ in the interim. Despite this growth, much of California (39-40\%) still contains habitat we would expect mountain lions to use to some extent. Our work demonstrates that it is possible to maintain large tracts of suitable habitat for large carnivore populations, even in the most populous state in the country. Yet, given continued projections of human population growth in California for the future (State of California Department of Finance 2019), investigation of the thresholds of adaptability of this wide-ranging and generalist large carnivore is warranted. There is cause for concern because half (50\%) of the habitat we identified is potentially subject to development. Further, in some regions of California, much of these protected lands occur within a fragmented landscape and lack adequate connectivity to one another (Spencer et al. 2010, Zeller et al. 2017). Lastly, wildlife managers in California will also need to begin considering changes in habitat suitability and availability due to effects of climate change, which can manifest through long-term drought and result in or occur in combination with large-scale high-intensity wildfires. These factors have the potential to alter the amount and distribution of suitable habitat for mountain lions in California (Jennings et al. 2016).

Wildlife habitat conservation efforts are most successful when attempting to maintain integrity of habitat that is of value to the target wildlife species or community those efforts seek to benefit (Rabinowitz and Zeller 2010, Morrison and Matthewson 2015). In some areas of California, habitat fragmentation threatens viability of mountain lion populations (Burdett et al. 2010). For example, the central coast (i.e., San Luis Obispo and Monterey counties) of California has large amounts of suitable mountain lion habitat (Fig. 3D,E); however, this area is undergoing rapid development (Thorne et al. 2006). This area has few large blocks of conserved lands (e.g., U.S. Forest Service), relative to other parts of the state, to help guard against habitat fragmentation. Our integrated statewide habitat selection maps, overlaid with land ownership layers, could be used to prioritize conservation of suitable habitat potentially subject to development to ensure against increasing fragmentation or restore connectivity. Furthermore, given the wideranging nature of mountain lions, conserving suitable mountain lion habitat serves to benefit numerous other species and helps maintain local biodiversity, connectivity, and ecosystem processes in general (Cougar Management Guidelines Working Group 2005, Thorne et al. 2006). Finally, although secure habitat is essential for long-term persistence of mountain lions in California, habitat alone is not enough. Large carnivore persistence in areas with high human populations are strongly dependent on human tolerance and management policy (Linnell et al. 2001).

\section{MANAGEMENT IMPLICATIONS}

Given that much of California is suitable mountain lion habitat, we recommend increased educational outreach efforts communicating the fact that many people live in or near suitable mountain lion habitat and should act accordingly to reduce conflict. In addition, future research examining aspects of mountain lion ecology should go beyond seeking to primarily understand mountain lion habitat selection patterns given that mountain lion habitat selection was largely consistent across a diversity of environmental conditions. Consistency in mountain lion habitat selection patterns across an array of environmental conditions could be used to facilitate development and use of more costeffective non-invasive population estimation techniques for this elusive and wide-ranging large carnivore. Our results indicate habitat treatments are potentially a viable option for wildlife managers to reduce mountain lion predation on declining or socially and economically important ungulate species.

\section{ACKNOWLEDGMENTS}

We thank M. W. Kenyon for the invaluable support and guidance in directing this research. We also thank the 3 anonymous reviewers who provided excellent feedback and helped to greatly improve the paper. Lastly, we thank the 
countless field technicians and volunteers that bolstered data collection efforts. Funding was provided by the Wildlife Restoration Fund to the California Department of Fish and Wildlife to J. A. Dellinger, D. J. Gammons, and S. G. Torres. Funding was provided by the Gordon and Betty Moore Foundation, NSF Grants 0963022 and 1255913 to C. C. Wilmers. Funding was provided to T. W. Vickers by California State Department of Parks and Recreation, The Nature Conservancy, McBeth Foundation, Anza Borrego Foundation, Nature Reserve of Orange County, National Science Foundation, Foothill/Eastern Transportation Corridor Agency, San Diego County Association of Governments Environ mental Mitigation Program, San Diego Foundation, Felidae Conservation Fund, Mountain Lion Foundation, Cougar Connection, and Santa Rosa Plateau Foundation. Funding was provided to H. U. Wittmer by the California Department of Fish and Wildlife big game program.

\section{LITERATURE CITED}

Arnold, T. W. 2010. Uninformative parameters and model selection using Akaike's Information Criterion. Journal of Wildlife Management 74:1175-1178.

Barton, K. 2019. MuMIn: Multi-model Inference. R package version 1.43.6. https://CRAN.R-project.org/package=MuMIn. Accessed 18 Oct 2018.

Bates, D., M. Maechler, B. Bolker, and S. Walker. 2015. Fitting linear mixed-effects models using lme4. Journal of Statistical Software 67:1-48.

Beausoleil, R. A., G. M. Koehler, B. T. Maletzke, B. N. Kertson, and R. B. Wielgus. 2013. Research to regulation: cougar social behavior as a guide for management. Wildlife Society Bulletin 37:680-688.

Benson, J. F. 2013. Improving rigour and efficiency of use-availability habitat selection analyses with systematic estimation of availability. Methods in Ecology and Evolution 4:244-251.

Benson, J. F., P. J. Mahoney, J. A. Sikich, L. E. Serieys, J. P. Pollinger, H. B. Ernest, and S. P. Riley. 2016. Interactions between demography, genetics, and landscape connectivity increase extinction probability for a small population of large carnivores in a major metropolitan area. Proceedings of the Royal Society B 283:20160957.

Beyer, H. L. 2015. Geospatial Modeling Environment (version 0.7.4.0) http://www.spatialecology.com/gme. Accessed 15 Oct 2018.

Blake, L. W., and E. M. Gese. 2016. Resource selection by cougars: influence of behavioral state and season. Journal of Wildlife Management 80:1205-1217.

Bose, S., T. D. Forrester, J. L. Brazeal, B. N. Sacks, D. S. Casady, and H. U. Wittmer. 2017. Implications of fidelity and philopatry for the population structure of female black-tailed deer. Behavioral Ecology 28:983-990.

Bose, S., T. D. Forrester, D. S. Casady, and H. U. Wittmer. 2018. Effect of activity state on habitat selection by black-tailed deer. Journal of Wildlife Management 82:1711-1724.

Boyce, M. S. 2006. Scale for resource selection functions. Diversity and Distributions 12:269-276.

Boyce, M. S., P. R. Vernier, S. E. Nielsen, and F. K. Schmiegelow. 2002. Evaluating resource selection functions. Ecological Modelling 157:281-300.

Burdett, C. L., K. R. Crooks, D. M. Theobald, K. R. Wilson, E. E. Boydston, L. M. Lyren, R. N. Fisher, T. W. Vickers, S. A. Morrison, and W. M. Boyce. 2010. Interfacing models of wildlife habitat and human development to predict the future distribution of puma habitat. Ecosphere 1:1-21.

Burnham, K. P., and D. R. Anderson. 2002. Model selection and multimodel inference: a practical information theoretic approach. Second edition. Springer-Verlag, Berlin, Germany.

California Department of Fish and Wildlife. 2016. Mule deer range. California Wildlife Habitat Relationships M181. California Department of Fish and Wildlife, Sacramento, USA.

California Fish and Game Commission. 2018. California fish and game code. Snape Legal Publishing, Sacramento, California, USA.
California Protected Areas Database. 2017. www.calands.org. Accessed Sep 2018.

Conner, M. M., T. R. Stephenson, D. W. German, K. L. Monteith, A. P. Few, and E. H. Bair. 2018. Survival analysis: informing recovery of Sierra Nevada bighorn sheep. Journal of Wildlife Management 82:1442-1458.

Cougar Management Guidelines Working Group. 2005. Cougar management guidelines. WildFutures, Bainbridge Island, Washington, USA.

Davidson, G. A., D. A. Clark, B. K. Johnson, L. P. Waits, and J. R. Adams. 2014. Estimating cougar densities in northeast Oregon using conservation detection dogs. Journal of Wildlife Management 78:1104-1114

Dellinger, J. A., N. W. Darby, and S. G. Torres. 2019. Factors influencing occupancy and detection rates of mountain lions in the Mojave Desert of California. Southwestern Naturalist 63:248-255.

Dellinger, J. A., E. R. Loft, R. C. Bertram, D. L. Neal, M. W. Kenyon, and S. G. Torres. 2018. Seasonal spatial ecology of mountain lions (Puma concolor) in the central Sierra-Nevada Mountains. Western North American Naturalist 78:143-156.

Dellinger, J. A., C. Proctor, T. D. Steury, M. J. Kelly, and M. R. Vaughan. 2013. Habitat selection of a large carnivore, the red wolf, in a humanaltered landscape. Biological Conservation 157:324-330.

Elbroch, L. M., and H. U. Wittmer. 2012. Puma spatial ecology in open habitats with aggregate prey. Mammalian Biology 77:377-384.

Forrester, T. D., and H. U. Wittmer. 2013. A review of the population dynamics of mule deer and black-tailed deer Odocoileus hemionus in North America. Mammal Review 43:292-308.

Getz, W. M., S. Fortmann-Roe, P. C. Cross, A. J. Lyons, S. J. Ryan, and C. C. Wilmers. 2007. LoCoH: nonparametric kernel methods for constructing home ranges and utilization distributions. Plos One 2:e207.

Grigione, M. M., P. Beier, R. A. Hopkins, N. D. Padley, W. D. Schonewald, and M. L. Johnson. 2002. Ecological and allometric determinants of home-range size for mountain lions (Puma concolor). Animal Conservation 5:317-324.

Gustafson, K. D., R. B. Gagne, T. W. Vickers, S. P. D. Riley, C. C. Wilmers, V. C. Bleich, B. M. Pierce, M. Kenyon, T. L. Drazenovich, J. A. Sikich, et al. 2019. Genetic source-sink dynamics among naturally structured and anthropogenically fragmented puma populations. Conservation Genetics 20:215-227.

Hamel, S., and S. D. Cote. 2007. Habitat use patterns in relation to escape terrain: are alpine ungulate females trading off better foraging sites for safety? Canadian Journal of Zoology 85:933-943.

Hebblewhite, M., D. G. Miquelle, A. A. Murzin, V. V. Aramilev, and D. G. Pikunov. 2011. Predicting potential habitat and population size for reintroduction of the Far Eastern leopards in the Russian Far East. Biological Conservation 144:2403-2413.

Hebblewhite, M., D. G. Miquelle, H. Robinson, D. G. Pikunov, Y. M. Dunishenko, V. V. Aramilev, I. G. Nikolaev, G. P. Salkina, I. V. Seryodkin, V. V. Gaponov, et al. 2014. Including biotic interactions with ungulate prey and humans improves habitat conservation modeling endangered Amur tigers in the Russian Far East. Biological Conservation 178:50-64.

Holbrook, J. D., J. R. Squires, L. E. Olson, N. J. DeCesare, and R. L. Lawrence. 2017. Understanding and predicting habitat for wildlife conservation: the case of Canada lynx at the range periphery. Ecosphere 8:e01939.

Hornocker, M., and S. Negri. 2010. Cougar: ecology and conservation. University of Chicago Press, Chicago, Illinois, USA.

Hudgens, B. R., J. F. Duquette, D. K. Garcelon, and M. P. Brinkman. 2016. Assessing pronghorn distribution, movements, and habitat use in northeastern California. Annual Report 2015-2016. California Department of Fish and Game, Sacramento, California, USA.

Hurley, M. A., J. W. Unsworth, P. Zager, M. Hebblewhite, E. O. Garton, D. M. Montgomery, J. R. Skalski, and C. L. Maycock. 2011. Demographic response of mule deer to experimental reduction of coyotes and mountain lions in southeastern Idaho. Wildlife Monographs 178:1-33.

Jennings, M. K., R. L. Lewison, T. W. Vickers, and W. M. Boyce. 2016. Puma response to the effects of fire and urbanization. Journal of Wildlife Management 80:221-234.

Johnson, D. H. 1980. The comparison of usage and availability measurements for evaluating resource preference. Ecology 61:65-71.

Johnson, C. J., S. E. Nielsen, E. H. Merrill, T. L. McDonald, and M. S. Boyce. 2006. Resource selection functions based on use-availability data: 
theoretical motivation and evaluation methods. Journal of Wildlife Management 70:347-357.

Johnson, H. E., M. Hebblewhite, T. R. Stephenson, D. W. German, B. M. Pierce, and V. C. Bleich. 2013. Evaluating apparent competition in limiting the recovery of an endangered ungulate. Oecologia 171:295-307.

Keating, K. A., and S. Cherry. 2004. Use and interpretation of logistic regression in habitat-selection studies. Journal of Wildlife Management 68:774-789.

Lehman, C. P., C. T. Rota, M. A. Rumble, and J. J. Millspaugh. 2017. Characteristics of successful puma kill sites of elk in the Black Hills, South Dakota. Wildlife Biology 2017:wlb.00248. https://doi.org/10. 2981/wlb.00248.

Linnell, J. D. C., J. E. Swenson, and R. Anderson. 2001. Predators and people: conservation of large carnivores is possible at high human densities if management policy is favourable. Animal Conservation Forum 4:345-349.

Loft, E. R., and V. C. Bleich. 2014. History of the conservation of critical deer ranges in California: concepts and terminology. California Fish and Game 100:451-472.

Long, R. A., P. MacKay, W. J. Zielinski, and J. C. Ray. 2012. Noninvasive survey methods for carnivores. Island Press, Washington, D.C., USA.

Manly, B. F. J., L. L. McDonald, D. L. Thomas, T. L. McDonald, and W. P. Erickson. 2002. Resource selection by animals: statistical design and analysis for field studies, second edition. Kluwer Academic Publishers, Norwell, Massachusetts, USA.

Mattson, D. J. 2014. State-level management of a common charismatic predator: mountain lions of the west. Pages 29-64 in S. G. Clark and M. B. Rutherford, editors. Large carnivore conservation: integrating science and policy in North America. University of Chicago Press, Chicago, Illinois, USA.

McClanahan, K. A., B. N. Duplisea, J. A. Dellinger, and M. W. Kenyon. 2017. Documentation of mountain lion occurrence and reproduction in the Sacramento Valley of California. California Fish and Game 103:7-14.

Mendiburu, F. 2019. Agricolae: Statistical procedures for agricultural research. $\mathrm{R}$ package version 1.3-0. https://CRAN.R-project.org/package= agricolae. Accessed 18 Oct 2018.

Morris, L. R., K. M. Proffitt, and J. K. Blackburn. 2016. Mapping resource selection functions in wildlife studies: concerns and recommendations. Applied Geography 76:173-183.

Morrison, M. L., and H. A. Matthewson. 2015. Wildlife habitat conservation: concepts, challenges, and solutions. Johns Hopkins University Press, Baltimore, Maryland, USA.

National Land Cover Database. 2011. NLCD 2011 Land Cover (CONUS). https://www.mrlc.gov/data/nlcd-2011-land-cover-conus-0. Accessed Sep 2018.

Nielson, R. M., B. F. J. Manly, L. L. McDonald, H. Sawyer, and T. L. McDonald. 2009. Estimating habitat selection when GPS fix success is less than 100\%. Ecology 90:2956-2962.

Orlando, A. M. 2008. Impacts of rural development on puma ecology in California's Sierra Nevada. Dissertation, University of California, Davis, California, USA.

Pierce, B. M., and V. C. Bleich. 2003. Mountain lion. Pages 744-757 in G. A. Feldhamer, B. C. Thompson and J. A. Chapman, editors. Wild mammals of North America: biology, management, and conservation, second edition. Johns Hopkins University Press, Baltimore, Maryland, USA.

Pierce, B. M., V. C. Bleich, J. D. Wehausen, and R. T. Bowyer. 1999. Migratory patterns of mountain lions: implications for social regulation and conservation. Journal of Mammalogy 80:986-992.
Proffitt, K. M., J. F. Goldberg, M. Hebblewhite, R. Russell, B. S. Jimenez, H. S. Robinson, K. Pilgrim, and M. K. Schwartz. 2015. Integrating resource selection into spatial capture-recapture models for large carnivores. Ecosphere 6:1-15.

R Core Team. 2017. R: a language and environment for statistical computing. R foundation for statistical computing, Vienna, Austria.

Rabinowitz, A., and K. A. Zeller. 2010. A range-wide model of landscape connectivity and conservation for the jaguar, Panthera onca. Biological Conservation 143:939-945.

Robinson, K. F., A. K. Fuller, J. E. Hurst, B. L. Swift, A. Kirsch, J. Farquhar, D. J. Decker, and W. F. Siemer. 2016. Structured decision making as a framework for large-scale wildlife harvest management decisions. Ecosphere 7:12.

Royle, J. A., R. B. Chandler, R. Sollmann, and B. Gardner. 2013. Spatial capture-recapture. Academic Press, Cambridge, Massachusetts, USA.

Ryder, T. J. 2018. State wildlife management and conservation. Johns Hopkins University Press, Baltimore, Maryland, USA.

Sawyer, J. O., T. Keehler-Wolf, and J. M. Evens. 2009. A manual of California vegetation. California Native Plant Society, Sacramento, USA.

Smith, J. A., Y. Wang, and C. C. Wilmers. 2015. Top carnivores increase their kill rates on prey as a response to human-induced fear. Proceedings of the Royal Society of London B: Biological Sciences 282:20142711.

Spencer, W. D., P. Beier, K. Penrod, K. Winters, C. Paulman, H. Rustigian-Rosmos, J. Strittholt, M. Parisi, and A. Pettler. 2010. California essential habitat connectivity project. Prepared for California Department of Transportation, California Department of Fish and Game, and Federal Highways Administration, Sacramento, USA.

State of California Department of Finance. 2019. State population projections (2010-2060). http://www.dof.ca.gov/Forecasting/Demographics/ projections/. Accessed 20 May 2019.

Thorne, J. H., D. Cameron, and J. F. Quinn. 2006. A conservation design for the central coast of California and the evaluation of mountain lion as an umbrella species. Natural Areas Journal 26:137-148.

Torres, S. G., T. M. Mansfield, J. E. Foley, T. Lupo, and A. Brinkhaus. 1996. Mountain lion and human activity in California: testing speculations. Wildlife Society Bulletin 24:451-460.

U.S. Census Bureau. 2017. TIGER/Line ${ }^{\circledR}$ Shapefiles. https://www.census. gov/geo/maps-data/data/tiger-line.html. Accessed Sep 2018.

U.S. Geological Survey. 2017. National elevation database. http:// nationalmap.gov/elevation.html. Accessed Sep 2018.

Vickers, T. W., J. N. Sanchez, C. K. Johnson, S. A. Morrison, R. Botta, T. Smith, B. S. Cohen, P. R. Huber, H. B. Ernest, and W. M. Boyce. 2015. Survival and mortality of pumas (Puma concolor) in a fragmented, urbanizing landscape. Plos One 9:e0131490.

Warren, M. J., D. O. Wallin, R. A. Beausoleil, and K. I. Warheit. 2016. Forest cover mediates genetic connectivity of northwestern cougars. Conservation Genetics 17:1011-1024.

Wilmers, C. C., Y. Wang, B. Nickel, P. Houghtaling, Y. Shakeri, M. L. Allen, J. Kermish-Wells, V. Yovovich, and T. Williams. 2013. Scale dependent behavioral responses to human development by a large predator, the puma. PLoS One 8:e60590.

Zeller, K. A., T. W. Vickers, H. B. Ernest, and W. M. Boyce. 2017. Multi-level, multi-scale resource selection functions and resistance surfaces for conservation planning: pumas as a case study. PloS One 12: e0179570.

Associate Editor: Kerry Nicholson. 